\title{
Infertility treatment and risk of severe maternal morbidity: a propensity score- matched cohort study
}

\author{
Natalie Dayan MD MSc, K.S. Joseph MD PhD, Deshayne B. Fell PhD, Carl A. Laskin MD, Olga Basso PhD, \\ Alison L. Park MSc, Jin Luo MSc, Jun Guan MSc, Joel G. Ray MD MSc
}

Cite as: CMAJ 2019 February 4;191:E118-27. doi: 10.1503/cmaj.181124

Visual abstract available at www.cmaj.ca/lookup/suppl/doi:10.1503/cmaj.181124/-/DC2.

\section{ABSTRACT \\ BACKGROUND: The extent to which infertility treatment predicts severe maternal morbidity is not well known. We examined the association between infertility treatment and severe maternal morbidity in pregnancy and the postpar- tum period.}

METHODS: We conducted a cohort study using population-based registries from Ontario between 2006 and 2012. Pregnancies achieved using infertility treatment (ovulation induction, intrauterine insemination or in vitro fertilization with or without intracytoplasmic sperm injection) were compared with unassisted pregnancies using propensity score matching, based on demographic, reproductive and obstetric factors. The primary outcome was a validated composite of severe maternal morbidity or maternal death from 20 weeks' gestation to 42 days postpartum. We also calculated the odds ratio of a woman having 1 , 2 , or 3 or more severe maternal morbidity indicators in relation to invasive (e.g., in vitro fertilization) or noninvasive (e.g., intrauterine insemination) infertility treatment.

RESULTS: We matched 11546 infertility treatment pregnancies with 47553 untreated pregnancies. Severe maternal morbidity or maternal death occurred in 356 infertility-treated pregnancies (30.8 per 1000 deliveries) versus 1054 untreated pregnancies (22.2 per 1000 deliveries); relative risk
1.39 (95\% confidence interval $[\mathrm{Cl}] 1.23-$ 1.56). The likelihood of a woman having 3 or more severe maternal morbidity indicators was increased in women who received invasive infertility treatment (odds ratio [OR] 2.28, 95\% Cl $1.56-3.33)$ but not in those who received noninvasive infertility treatment (OR 0.99, 95\% Cl 0.57-1.72).

INTERPRETATION: Women who undergo infertility treatment, particularly in vitro fertilization, are at somewhat higher risk of severe maternal morbidity or death. Efforts are needed to identify patient- and treatment-specific predictors of severe maternal morbidity that may influence the type of treatment a woman is offered. nfertility affects 1 in 6 Canadian couples, many of whom turn to infertility treatment. These include pharmacologic ovulation induction, intrauterine insemination, and more invasive assisted reproductive technologies, such as in vitro fertilization. In vitro fertilization often follows intense rounds of ovarian hyperstimulation, oocyte retrieval and intracytoplasmic sperm injection. ${ }^{1}$ Assisted reproductive technology accounts for about 18000 pregnancies in Canada each year, with $1 \%-4 \%$ of births conceived using infertility treatment., ${ }^{2,3}$ Although infertility treatment improves the chances of a pregnancy among infertile couples, it may have unintended consequences for mother and newborn, such as a higher risk of preterm birth, low birth weight and cesarean delivery that are independent of age and plurality. ${ }^{1,4-6}$ Canadian public funding programs for in vitro fertilization launched in the provinces of Quebec (2010-2015) ${ }^{7}$ and Ontario (started in 2015 and ongoing) ${ }^{8}$ have increased in vitro fertilization access among ethnically and socially diverse groups of women. ${ }^{9}$ However, the effect on maternal health of infertility treatment in general - and in vitro fertilization in particular - is understudied. 
Severe maternal morbidity refers to a broad set of conditions that identify women who experience a near-fatal event during, or within 42 days of, a pregnancy. Severe maternal morbidity is more common than maternal mortality: rates in Canada are about 15 per 1000 and 10 per 100000 hospital deliveries, respectively. ${ }^{10,11}$ Thus, severe maternal morbidity is the preferred indicator for assessing risk factors or interventions that can influence maternal health. ${ }^{11}$ The association between assisted reproductive technologies and severe maternal morbidity has been investigated recently in 3 studies in the United States, each reporting an approximate doubling of the risk of severe maternal morbidity among women with pregnancies conceived through assisted reproductive technologies compared to those with pregnancies conceived without. ${ }^{12-14}$ However, we are not aware of any studies that have assessed whether severe maternal morbidity risk varies by type of infertility treatment while simultaneously addressing confounding by indication. Additionally, it is unclear if women who conceived using infertility treatment have more indicators of severe maternal morbidity (i.e., a marker of greater severity). Our aim was to address these questions within a large Canadian population.

\section{Methods}

We followed the Strengthening the Reporting of Observational Studies in Epidemiology (STROBE) guideline for reporting of observational studies. ${ }^{15}$

\section{Study population and data sources}

We considered women aged 18-60 years with a hospital delivery, who were residents of Ontario and registered within Ontario's universal health insurance program (OHIP). We excluded women whose pregnancy ended as an ectopic pregnancy, induced abortion or miscarriage, and randomly sampled 1 live birth or stillbirth at 20 or more weeks' gestation per woman (Figure 1). To address potential confounding by indication, we matched about 5 untreated pregnancies to each infertility treatment pregnancy using a propensity score. The propensity score was generated by including all baseline characteristics in a logistic regression model; pregnancies were matched without replacement using the greedy method, with a caliper width score of \pm 0.2 standard deviations. ${ }^{16}$

We identified all live births and stillbirths in Ontario between Apr. 1, 2006, and Mar. 31, 2012, within the Better Outcomes Registry \& Network (BORN) Ontario legacy data sets (www.bornontario. $\mathrm{ca} /$ en/data/data-dictionary/legacy-datasets/). Linked data beyond fiscal year 2012 were unavailable in the registry at the time of this study. This registry captures more than $99 \%$ of hospital births in the province, and has been previously validated for data completeness and accuracy. ${ }^{17}$ We used the Registered Persons Database, the Permanent Resident Database (Immigration, Refugees and Citizenship Canada) and the Discharge Abstract Database (Canadian Institute for Health Information) to capture maternal demographics, preexisting health conditions, and

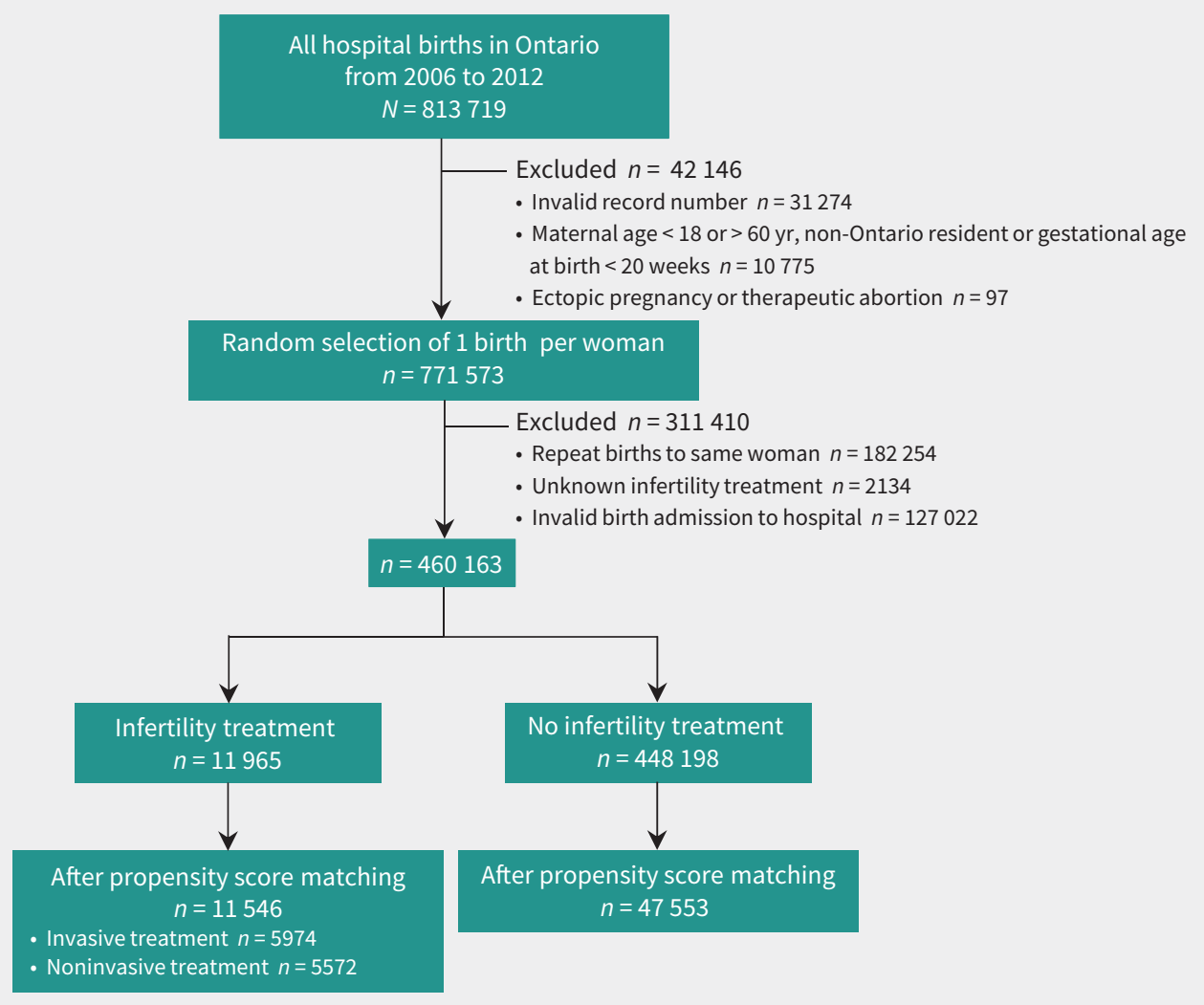

Figure 1: Flow diagram for the creation of the propensity score-matched study cohort. 
diagnoses and procedures documented during an admission to hospital (Appendix 1, available at www.cmaj.ca/lookup/suppl/ doi:10.1503/cmaj.181124/-/DC1). The data sets were linked using unique encoded identifiers and analyzed at ICES. Diagnostic codes were based on the Canadian version of the International Statistical Classification of Diseases and Related Health Problems, 10th Revision (ICD-10-CA), and procedural codes were based on the Canadian Classification of Health Interventions (CCI).

\section{Exposure and outcome variables}

We categorized a pregnancy as "exposed" if conceived using any form of infertility treatment, including in vitro fertilization and related intracytoplasmic sperm injection, intrauterine insemination or ovulation induction alone. In addition, we assessed the association between infertility treatment and the outcome of severe maternal morbidity, stratifying by invasive treatment (in vitro fertilization with or without intracytoplasmic sperm injection) or noninvasive treatment (intrauterine insemination or ovulation induction alone).

The primary study outcome was the occurrence of a composite severe maternal morbidity or maternal death between 20 weeks' gestation and 42 days after hospital discharge following delivery. The list of conditions included in the composite, developed by the Canadian Perinatal Surveillance System ${ }^{18}$ and recently updated, comprises 44 unique indicators of severe maternal morbidity (Appendix 1). Previous validation of this composite measure included assessments of case fatality rates and maternal length of hospital stay greater than 7 days for each component indicator. ${ }^{18}$ Secondary outcomes included the 5 most common individual indicators of severe maternal morbidity and all-cause maternal mortality between 42 and 365 days postpartum.

\section{Statistical analysis}

We used standardized differences to compare assisted and unassisted pregnancies, with a value of greater than 0.10 suggesting a meaningful difference. ${ }^{19}$ Rates of all outcomes were expressed per 1000 deliveries. We used modified Poisson regression to generate relative risks (RRs) and 95\% confidence intervals (Cls) for severe maternal morbidity or death, comparing the treated group with their counterparts who conceived without infertility treatment (the reference group). We identified the 5 most common indicators of severe maternal morbidity in the study population and calculated the RR for each. In addition to examining overall infertility treatment, we estimated RRs for noninvasive (intrauterine insemination and ovulation induction) and invasive treatment (in vitro fertilization with or without intracytoplasmic sperm injection) separately. The main model was further stratified by maternal age ( $<40 \mathrm{or} \geq 40 \mathrm{yr}$ ) and by singleton or multiple gestation, with propensity score rematching in each stratum.

We considered women with more than 1 indicator of severe maternal morbidity to have more severe morbidity and a higher likelihood of death than women with a single indicator. Accordingly, we used multinomial logistic regression (accounting for matching by whether pregnancy had no infertility treatment) to estimate the odds ratio (OR) of a woman having 1, 2, or 3 or more indicators of severe maternal morbidity (compared with none), in relation to infertility treatment versus no infertility treatment. We repeated the same modelling approach when comparing treatment subtype (invasive v. noninvasive infertility treatment) versus no treatment (the referent). In these models, death was not included in the outcome.

\section{Ethics approval}

The use of data in this project was authorized under section 45 of Ontario's Personal Health Information Protection Act, which does not require review by a research ethics board.

\section{Results}

We identified 813719 births in Ontario during the study period (Figure 1). After exclusions, and before matching, there were 11965 women with a pregnancy conceived through infertility treatment and 448198 women with a pregnancy conceived without treatment (Figure 1, Table 1). The women given infertility treatment were older and had higher incomes, and a greater proportion were nulliparous or pregnant with multiple gestation (Table 1). After propensity score matching, there were 11546 pregnancies that resulted from infertility treatment and 47553 untreated pregnancies, with minimal differences in characteristics between the 2 matched groups (Figure 1, Table 1, Appendix 3, available at www.cmaj.ca/lookup/suppl/ doi:10.1503/cmaj.181124/-/DC1).

In the study cohort before propensity score matching, there were 387 pregnancies achieved through infertility treatment that were affected by severe maternal morbidity or death (32.3 per 1000), compared with 6689 cases of severe maternal morbidity or death in the untreated group (14.9 per 1000), yielding a crude RR of 2.17 (95\% Cl 1.96-2.40). Death at 42 days postpartum to 365 days postpartum occurred in 6 women who were given infertility treatment (rate 0.3 per 1000) and in 97 women who did not (0.2 per 1000), a crude RR of 1.54 (95\% Cl 0.57-4.20).

In the propensity-matched cohort, severe maternal morbidity or death occurred in 356 pregnancies resulting from infertility treatment (30.8 per 1000) and in 1054 untreated pregnancies (22.2 per 1000); adjusted RR 1.39 (95\% Cl 1.23-1.56; Figure 2). Severe maternal morbidity or death occurred in 121 pregnancies achieved through noninvasive treatment and 235 pregnancies achieved through invasive treatment (21.7 and 39.3 per 1000 , respectively), yielding adjusted RRs of 0.98 (95\% Cl $0.81-$ 1.18 ) and 1.77 (95\% Cl 1.54-2.03), respectively, compared with untreated pregnancies (Figure 3 ). The absolute risk of severe maternal morbidity or death in relation to use of infertility treatment was more pronounced in those 40 years and older and in those with a multiple pregnancy (Table 2). However, relative rates of severe maternal morbidity or death by treatment status were similar among women less than 40 versus 40 or more years of age, and among women with singleton versus multiple pregnancies.

In the matched cohort, death from 20 weeks' gestation up to 42 days postpartum occurred in fewer than 6 women who used infertility treatment $(\leq 0.5$ per 1000$)$, and in fewer than 6 women 
Table 1 (part 1 of 2): Baseline characteristics of the cohort before and after propensity score matching

\begin{tabular}{|c|c|c|c|c|c|c|}
\hline \multirow[b]{2}{*}{ Characteristic } & \multicolumn{3}{|c|}{ Unmatched cohort } & \multicolumn{3}{|c|}{ Propensity score-matched cohort } \\
\hline & $\begin{array}{c}\text { No. }(\%)^{\star} \text { of } \\
\text { women with } \\
\text { infertility } \\
\text { treatment } \\
n=11965\end{array}$ & $\begin{array}{c}\text { No. }(\%)^{\star} \text { of } \\
\text { women with no } \\
\text { infertility } \\
\text { treatment } \\
n=448198\end{array}$ & $\begin{array}{l}\text { Standardized } \\
\text { difference }\end{array}$ & $\begin{array}{c}\text { No. }(\%)^{\star} \text { of } \\
\text { women with } \\
\text { infertility } \\
\text { treatment } \\
n=11546\end{array}$ & $\begin{array}{c}\text { No. }(\%)^{\star} \text { of } \\
\text { women with } \\
\text { no infertility } \\
\text { treatment } \\
n=47553\end{array}$ & $\begin{array}{c}\text { Standardized } \\
\text { difference }\end{array}$ \\
\hline \multicolumn{7}{|l|}{ Year } \\
\hline 2006 & $1225(10.2)$ & $62249(13.9)$ & 0.11 & $1197(10.4)$ & $5055(10.6)$ & 0.01 \\
\hline 2007 & $1387(11.6)$ & $70515(15.7)$ & 0.12 & $1351(11.7)$ & $5712(12.0)$ & 0.01 \\
\hline 2008 & $1647(13.8)$ & $73990(16.5)$ & 0.08 & 1609 (13.9) & $6882(14.5)$ & 0.02 \\
\hline 2009 & $2150(18.0)$ & $78806(17.6)$ & 0.01 & $2066(17.9)$ & $8148(17.1)$ & 0.02 \\
\hline 2010 & $2708(22.6)$ & 80154 (17.9) & 0.12 & $2588(22.4)$ & $10637(22.4)$ & 0.0 \\
\hline 2011 & $2848(23.8)$ & $82484(18.4)$ & 0.13 & $2735(23.7)$ & $11119(23.4)$ & 0.01 \\
\hline \multicolumn{7}{|c|}{ Maternal age at index pregnancy, yr } \\
\hline Mean \pm SD & $34.2 \pm 4.9$ & $30.1 \pm 5.5$ & 0.79 & $34.0 \pm 4.8$ & $33.6 \pm 5.0$ & 0.09 \\
\hline $18-24$ & $213(1.8)$ & $74300(16.6)$ & 0.53 & $213(1.8)$ & $1791(3.8)$ & 0.12 \\
\hline $25-34$ & $6226(52.0)$ & $277239(61.9)$ & 0.20 & $6115(53.0)$ & $24787(52.1)$ & 0.02 \\
\hline $35-39$ & $3913(32.7)$ & $79466(17.7)$ & 0.35 & $3758(32.5)$ & $15214(32.0)$ & 0.01 \\
\hline $40-44$ & $1327(11.1)$ & $16489(3.7)$ & 0.29 & $1224(10.6)$ & $5422(11.4)$ & 0.03 \\
\hline$\geq 45$ & $286(2.4)$ & $704(0.2)$ & 0.20 & $236(2.0)$ & $339(0.7)$ & 0.11 \\
\hline \multicolumn{7}{|c|}{ Neighbourhood income quintilet } \\
\hline 1 (lowest) & $1370(11.5)$ & $100445(22.4)$ & 0.30 & $1343(11.6)$ & $5797(12.2)$ & 0.02 \\
\hline 2 & $1952(16.3)$ & $90596(20.2)$ & 0.10 & $1903(16.5)$ & $7970(16.8)$ & 0.01 \\
\hline 3 & $2598(21.7)$ & $92896(20.7)$ & 0.02 & $2509(21.7)$ & $10480(22.0)$ & 0.01 \\
\hline 4 & $3231(27.0)$ & $92285(20.6)$ & 0.15 & $3104(26.9)$ & $12653(26.6)$ & 0.01 \\
\hline 5 (highest) & $2789(23.3)$ & $69907(15.6)$ & 0.20 & $2663(23.1)$ & $10541(22.2)$ & 0.02 \\
\hline \multicolumn{7}{|c|}{ Maternal world region of origin†‡ } \\
\hline Africa & $134(1.1)$ & $8281(1.8)$ & 0.06 & $129(1.1)$ & $534(1.1)$ & 0.0 \\
\hline Canada & $8967(74.9)$ & $323062(72.1)$ & 0.06 & $8650(74.9)$ & $35591(74.8)$ & 0.0 \\
\hline Caribbean & $102(0.9)$ & $7504(1.7)$ & 0.07 & $98(0.8)$ & $414(0.9)$ & 0.0 \\
\hline East Asia & $444(3.7)$ & $27705(6.2)$ & 0.11 & $437(3.8)$ & $1882(4.0)$ & 0.01 \\
\hline Hispanic America & $233(1.9)$ & $9945(2.2)$ & 0.02 & $223(1.9)$ & $943(2.0)$ & 0.0 \\
\hline Middle East & $352(2.9)$ & $12168(2.7)$ & 0.01 & $337(2.9)$ & $1363(2.9)$ & 0.0 \\
\hline South Asia & $1080(9.0)$ & $40382(9.0)$ & 0 & $1039(9.0)$ & $4324(9.1)$ & 0.0 \\
\hline $\begin{array}{l}\text { Western nations and } \\
\text { Europe }\end{array}$ & $653(5.5)$ & $19122(4.3)$ & 0.06 & $633(5.5)$ & $2502(5.3)$ & 0.01 \\
\hline \multicolumn{7}{|l|}{ Comorbidities } \\
\hline BMI, median (IQR), $\mathrm{kg} / \mathrm{m}^{2} \S$ & $25(22-30)$ & $25(22-29)$ & 0.08 & $25(22-30)$ & $25(22-30)$ & 0.09 \\
\hline $\begin{array}{l}\text { Obesity at any visit (BMI > } \\
30 \mathrm{~kg} / \mathrm{m}^{2} \text { ) }\end{array}$ & $731(6.1)$ & $22383(5.0)$ & 0.05 & $716(6.2)$ & $2842(6.0)$ & 0.01 \\
\hline Cardiac disease & $411(3.4)$ & $12177(2.7)$ & 0.04 & $394(3.4)$ & $1511(3.2)$ & 0.01 \\
\hline Stroke & $12(0.1)$ & $403(0.1)$ & 0 & $12(0.1)$ & $40(0.1)$ & 0.01 \\
\hline Hypertension & $701(5.9)$ & $16267(3.6)$ & 0.11 & $657(5.7)$ & $2515(5.3)$ & 0.02 \\
\hline Diabetes mellitus & 1478 (12.4) & $33524(7.5)$ & 0.16 & $1412(12.2)$ & $5342(11.2)$ & 0.03 \\
\hline Renal disease & $17(0.1)$ & $448(0.1)$ & 0.01 & $16(0.1)$ & $54(0.1)$ & 0.01 \\
\hline HIV & $9(0.1)$ & $411(0.1)$ & 0.01 & $9(0.1)$ & $32(0.1)$ & 0.0 \\
\hline Tobacco use $e^{\star \star}$ & 408 (3.4) & $54507(12.2)$ & 0.33 & 406 (3.5) & $1820(3.8)$ & 0.02 \\
\hline
\end{tabular}


Table 1 (part 2 of 2): Baseline characteristics of the cohort before and after propensity score matching

Unmatched cohort

\begin{tabular}{|c|c|c|c|c|c|c|}
\hline Characteristic & $\begin{array}{c}\text { No. }(\%)^{\star} \text { of } \\
\text { women with } \\
\text { infertility } \\
\text { treatment } \\
n=11965\end{array}$ & $\begin{array}{c}\text { No. }(\%)^{\star} \text { of } \\
\text { women with no } \\
\text { infertility } \\
\text { treatment } \\
n=448198\end{array}$ & $\begin{array}{l}\text { Standardized } \\
\text { difference }\end{array}$ & $\begin{array}{c}\text { No. }(\%)^{\star} \text { of } \\
\text { women with } \\
\text { infertility } \\
\text { treatment } \\
n=11546\end{array}$ & $\begin{array}{c}\text { No. }(\%)^{\star} \text { of } \\
\text { women with } \\
\text { no infertility } \\
\text { treatment } \\
n=47553\end{array}$ & $\begin{array}{c}\text { Standardized } \\
\text { difference }\end{array}$ \\
\hline Major psychiatric condition & $1967(16.4)$ & $73967(16.5)$ & 0 & $1887(16.3)$ & $7376(15.5)$ & 0.02 \\
\hline Endometriosis & $139(1.2)$ & $1435(0.3)$ & 0.1 & $133(1.2)$ & $301(0.6)$ & 0.06 \\
\hline Polycystic ovarian & $6(0.1)$ & $15(0.0)$ & 0.03 & $\leq 5(0.0)$ & $6(0.0)$ & 0.0 \\
\hline
\end{tabular}

syndrome

Pregnancy characteristics

Parity $\dagger$

0
1
$\geq 2$
No. of previous live births,
median (IQR)
No. of previous miscarriages $\dagger$
0
$1-2$
$\geq 3$

$8543(71.4)$
$2786(23.3)$
$635(5.3)$
$0(0-1)$

$8431(70.5)$

$3022(25.3)$

$511(4.3)$

Multiple gestation in the

index pregnancy

Type of infertility treatment in the index pregnancy

$\begin{array}{lr}\text { Intrauterine insemination } & 2892(24.2) \\ \text { Ovulation induction } & 2820(23.6) \\ \begin{array}{l}\text { In vitro fertilization } \\ \text { Intracytoplasmic sperm } \\ \text { injection }\end{array} & 5630(47.1) \\ \begin{array}{l}\text { No. of antenatal visits in } \\ \text { the index pregnancy, } \\ \text { median (IQR) }\end{array} & 22(17-29) \\ \end{array}$

Note: $\mathrm{BMI}=$ body mass index, $\mathrm{IQR}=$ interquartile range, $\mathrm{SD}=$ standard deviation

*Unless specified otherwise.

†Data missing in $<1 \%$.

†Appendix 2 (available at www.cmaj.ca/lookup/suppl/doi:10.1503/cmaj.181124/-/DC1) contains the definitions of each of the maternal world regions of origin

$\S$ Data were available for BMI for 383543 pregnancies in the unmatched cohort and 47939 pregnancies in the matched cohort.

१Congestive heart failure, congenital heart disease, coronary artery disease, cardiac dysthymia, chronic rheumatic heart disease or previous myocardial infarction

${ }^{\star \star}$ Defined as any use (yes/no) as of 20 weeks' gestation.

who did not ( $\leq 0.1$ per 1000), an adjusted RR of $4.12(95 \% \mathrm{Cl} 1.19$ to 14.22 ). Death at 42 days postpartum to 365 days postpartum occurred in fewer than 6 women who received infertility treatment ( $\leq 0.5$ per 1000) and in 11 women who did not receive treatment (0.2 per 1000), an adjusted RR of 1.12 (95\% Cl $0.31-4.03$ ) (data not shown).

The most common individual indicators of severe maternal morbidity were (in descending order) severe postpartum hemorrhage (i.e., requiring transfusion of red blood cells or other interventions), maternal admission to an intensive care unit (ICU), puerperal sepsis, hysterectomy and cardiac conditions (Figures 2 and 3). Each was more common in pregnancies achieved through infertility treatment than in untreated pregnancies (Figure 2). Significant associations between infertility treatment and the 3 most common indicators of severe maternal morbidity were observed among pregnancies achieved through invasive treatment, whereas no statistically significant associations were observed for noninvasive treatment (Figure 3).

The odds of having a greater number of indicators of severe maternal morbidity were higher among women who used infertility treatment compared with those who did not (Table 3). For example, the adjusted OR for having 3 or more indicators was 1.65 (95\% Cl 1.18-2.30). Furthermore, women who received invasive treatment had the highest OR for having 3 or more indicators 
of severe maternal morbidity (adjusted OR $2.28,95 \% \mathrm{Cl} 1.56-$ 3.33), whereas there was no association for noninvasive treatment (adjusted OR 0.99, 95\% Cl 0.57-1.72; Table 3).

\section{Interpretation}

In this large representative sample of women who became pregnant through all forms of infertility treatment, the risk of severe maternal morbidity or death was modestly increased relative to a propensity score-matched comparison group without infertility treatment. The higher risk of severe maternal morbidity was notable for severe postpartum hemorrhage, ICU admission and sepsis. Receipt of in vitro fertilization conferred the greatest burden of severe maternal morbidity or maternal death, whereas such increased risks were not evident for noninvasive infertility treatment.
After propensity score matching, the RR of severe maternal morbidity or death was attenuated from 2.17 to 1.39 , suggesting that some of the association between infertility treatment and severe maternal morbidity is explained by maternal factors rather than by the treatment. We and other researchers ${ }^{10}$ have shown that maternal age over 40 years confers a higher absolute risk of severe maternal morbidity or death, as does a multiple pregnancy. Nevertheless, the significant difference in the effect of in vitro fertilization compared with noninvasive treatment suggests that factors associated with in vitro fertilization may contribute to severe maternal morbidity.

This study used comprehensive and validated data sets capturing more than $99 \%$ of hospital births. ${ }^{22}$ The broad array of maternal variables included in the propensity score used for matching should have minimized confounding by indication. ${ }^{23}$
No. of women with outcome/no. of women at risk (rate per 1000)

Any SMM

No infertility treatment: $n=1054 / 47553$ (22.2)

Infertility treatment: $n=356 / 11546$ (30.8)

1.39 (1.23 to 1.56$)$

Postpartum hemorrhage procedures to the uterus or hysterectomy

\begin{abstract}
Maternal ICU admission
\end{abstract}

Puerperal sepsis

Hysterectomy

Cardiac conditions

All-cause maternal death from 20 wk gestation to $42 \mathrm{~d}$ postpartum
No infertility treatment: $n=320 / 47553(6.7)$

Infertility treatment: $n=132 / 11546$ (11.4)

1.70 (1.39 to 2.08 )

No infertility treatment: $n=219 / 47553$ (4.6)

Infertility treatment: $n=80 / 11546$ (6.9)

1.51 (1.17 to 1.94$)$

No infertility treatment: $n=144 / 47553$ (3.0)

Infertility treatment: $n=54 / 11546$ (4.7)

1.54 (1.13 to 2.10$)$

No infertility treatment: $n=172 / 47553$ (3.6)

Infertility treatment: $n=45 / 11546$ (3.9)

No infertility treatment: $n=94 / 47553(2.0)$

Infertility treatment: $n=30 / 11546$ (2.6)

$1.32(0.87$ to 1.98$)$

No infertility treatment: $n<6 / 47553(\leq 0.1)$

Infertility treatment: $n<6 / 11546(\leq 0.5)$

4.12 (1.19 to 14.22 )
$1.08(0.78$ to 1.50$)$

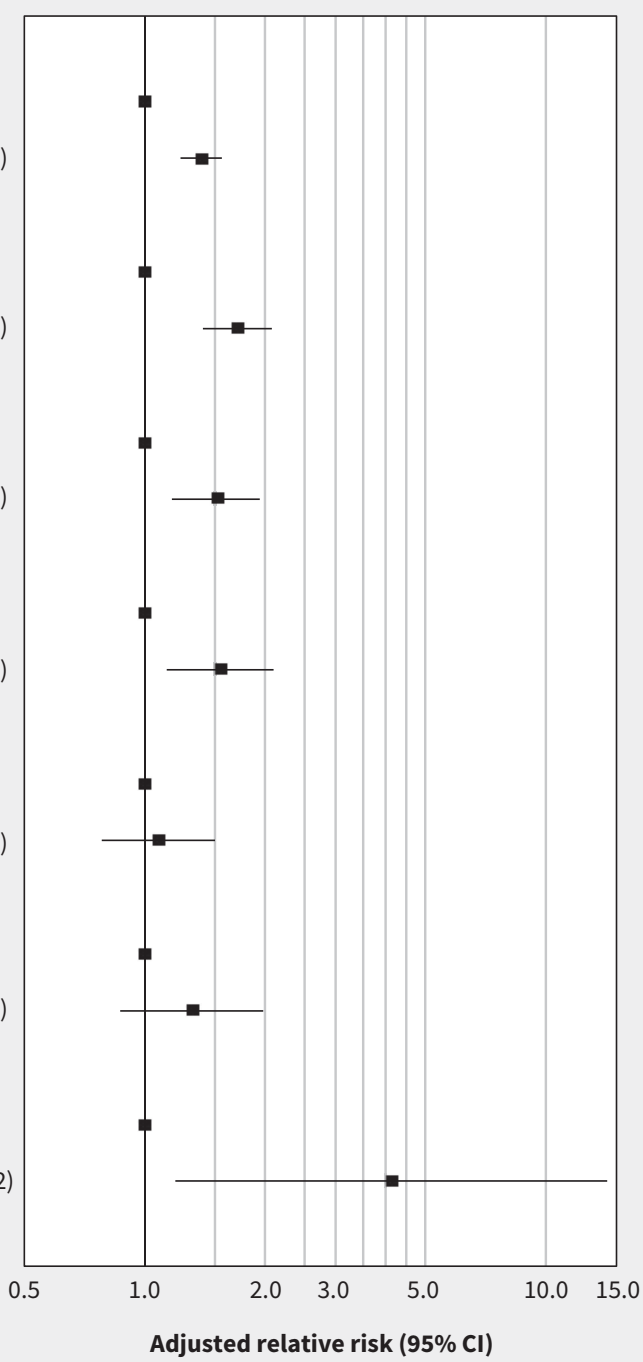

Figure 2: Risk of a woman having severe maternal morbidity or death between 20 weeks' gestation and 42 days after the index birth, in relation to receipt of infertility treatment within the index pregnancy, relative to no infertility treatment (propensity-matched cohort). Data are shown for the 5 most common subtypes of severe maternal morbidity. Note: $\mathrm{Cl}=$ confidence interval, $\mathrm{ICU}=$ intensive care $\mathrm{unit}, \mathrm{RBC}=\mathrm{red} \mathrm{blood}$ cells, $\mathrm{RR}=\mathrm{relative}$ risk, $\mathrm{SMM}=$ severe maternal morbidity. 
We evaluated not only severe maternal morbidity but also the number of severe maternal morbidity indicators. The list of severe maternal morbidity indicators used for Canadian perinatal surveillance is similar to that proposed for use in the US, including ICU admission, ${ }^{24}$ which is strongly predictive of maternal mortality. ${ }^{25}$

Others have previously examined the association between infertility treatment and severe maternal morbidity. In 2016, a retrospective cohort study reported that, among 1 million births in the US, including 14761 pregnancies achieved through assisted reproductive technologies, the adjusted RR for severe maternal morbidity was $2.3(95 \% \mathrm{Cl} 2.1-2.7)$ when comparing assisted reproductive technologies with no treatment. ${ }^{12}$ Unlike that study, which used a data source employing International Classification of Diseases, 9th revision (ICD-9) coding, our data source employed ICD-10-CA coding, which better classifies severe preeclampsia, procedures used to manage severe hemorrhagic complications and other indicators of severe maternal morbidity. In addition, we included socioeconomic factors in propensity score matching, such as income quintile and maternal country of origin, which also strongly predict severe maternal morbidity. ${ }^{20,21}$ Our study included only 1 randomly selected delivery per woman, thereby avoiding any potential overestimation of the risk of infertility treatment in repeat pregnancies. ${ }^{12}$ Another small single-centre study also
No. of women with outcome/no. of women at risk (rate per 1000)

No infertility treatment: $n=1054 / 47553(22.2)$

Any SMM

Noninvasive treatment: $n=121 / 5572$ (21.7) 0.98 (0.81 to 1.18)

Invasive treatment: $n=235 / 5974(39.3)$

1.77 (1.54 to 2.03$)$

\begin{abstract}
Postpartum hemorrhage with RBC transfusion, procedures to the uterus or hysterectomy
\end{abstract}

Maternal ICU admission

Puerperal sepsis

Hysterectomy

Cardiac conditions

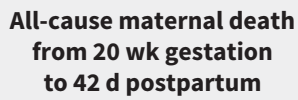

No infertility treatment: $n=320 / 47553(6.7)$

Noninvasive treatment: $n=41 / 5572$ (7.4) 1.09 (0.79 to 1.51 ) Invasive treatment: $n=91 / 5974$ (15.2) 2.26 (1.80 to 2.85 )

No infertility treatment: $n=219 / 47553$ (4.6)

Noninvasive treatment: $n=26 / 5572$ (4.7) 1.01 (0.68 to 1.52) Invasive treatment: $n=54 / 5974$ (9.0) 1.97 (1.46 to 2.64 )

No infertility treatment: $n=144 / 47553$ (3.0)

Noninvasive treatment: $n=21 / 5572$ (3.8) 1.24 (0.78 to 1.95)

Invasive treatment: $n=33 / 5974$ (5.5) 1.82 (1.25 to 2.66 )

No infertility treatment: $n=172 / 47553$ (3.6)

Noninvasive treatment: $n=14 / 5572$ (2.5) 0.70 (0.41 to 1.20 )

Invasive treatment: $n=31 / 5974$ (5.2) 1.44 (0.99 to 2.10 )

No infertility treatment: $n=94 / 47553(2.0)$

Noninvasive treatment: $n=13 / 5572$ (2.3) 1.18 (0.66 to 2.11) Invasive treatment: $n=17 / 5974$ (2.8) 1.44 (0.86 to 2.41 )

No infertility treatment: $n<6 / 47553(\leq 0.1)$

Noninvasive treatment: $n<6 / 5572$ ( $\leq 1.1) 3.41$ (0.66 to 17.58) Invasive treatment: $n<6 / 5974$ ( $\leq 1.0) 4.78$ (1.14 to 19.97 )

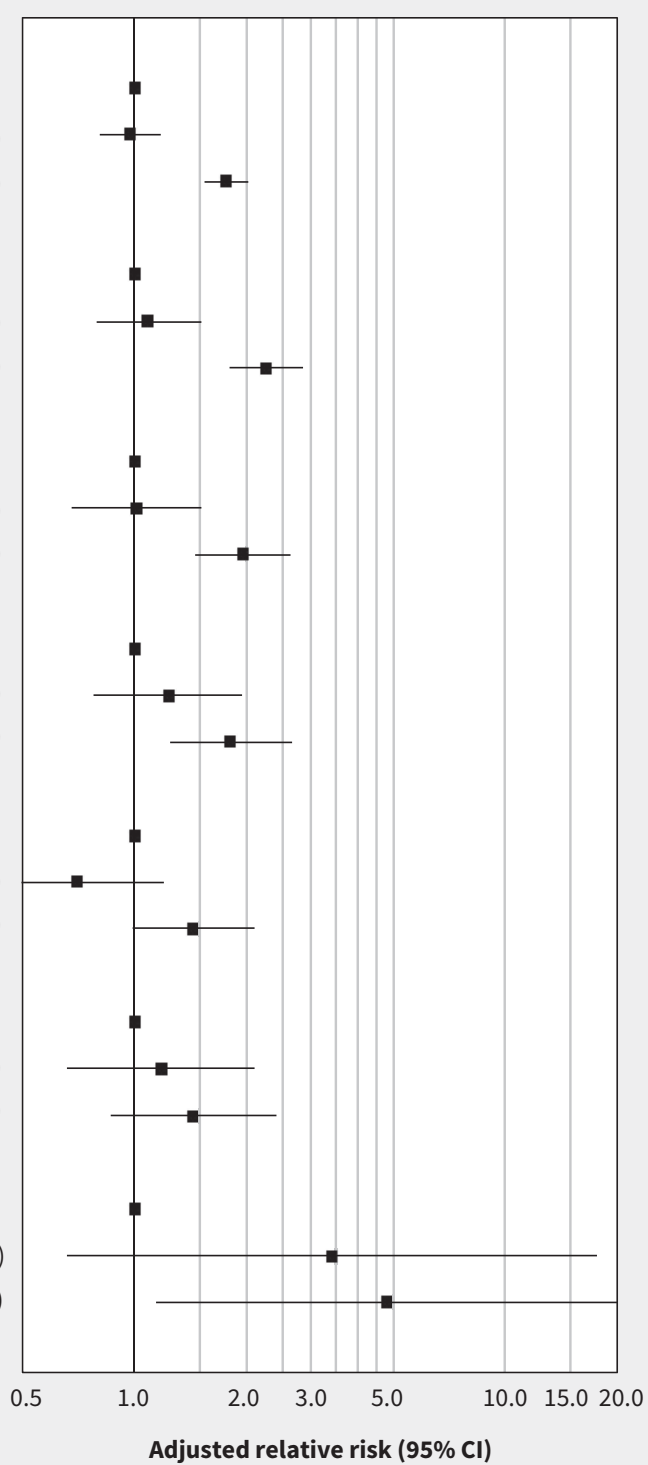

Figure 3: Risk of a woman having severe maternal morbidity or death between 20 weeks' gestation and 42 days after the index birth, in relation to receipt of noninvasive or invasive infertility treatment within the index pregnancy, each relative to no infertility treatment. Data are shown for the 5 most common indicators of severe maternal morbidity. Note: $\mathrm{Cl}=$ confidence interval, ICU = intensive care unit, $\mathrm{RBC}=\mathrm{red}$ blood cells, $\mathrm{RR}=$ relative risk, SMM = severe maternal morbidity. 
Table 2: Relative risk of a woman experiencing severe maternal morbidity or death between 20 weeks gestation and 42 days after the index birth, in relation to receipt of infertility treatment within the index pregnancy and relative to no infertility treatment

\begin{tabular}{|c|c|c|c|c|c|}
\hline \multirow[b]{2}{*}{ Stratification variable } & \multicolumn{2}{|c|}{$\begin{array}{c}\text { Women who received infertility } \\
\text { treatment* }\end{array}$} & \multicolumn{2}{|c|}{$\begin{array}{l}\text { Women who did not receive } \\
\text { infertility treatment* }\end{array}$} & \multirow[b]{2}{*}{$\begin{array}{c}\text { Relative risk }(95 \% \mathrm{CI}) \\
\text { of SMM or death }\end{array}$} \\
\hline & $\begin{array}{l}\text { No. with SMM } \\
\text { or who died }\end{array}$ & $\begin{array}{c}\text { No. at risk } \\
\text { (rate per 1000) }\end{array}$ & $\begin{array}{l}\text { No. with SMM } \\
\text { or who died }\end{array}$ & $\begin{array}{c}\text { No. at risk } \\
\text { (rate per 1000) }\end{array}$ & \\
\hline Age $<40$ yr & 279 & $10070(27.7)$ & 866 & $42448(20.4)$ & $1.36(1.19-1.55)$ \\
\hline Age $\geq 40 \mathrm{yr}$ & 73 & $1443(50.6)$ & 155 & $5046(30.7)$ & $1.64(1.25-2.16)$ \\
\hline Singleton pregnancy & 210 & $8933(23.5)$ & 798 & $40693(19.6)$ & $1.20(1.03-1.39)$ \\
\hline Multiple pregnancy & 135 & $2515(53.7)$ & 235 & $6696(35.1)$ & $1.52(1.23-1.88)$ \\
\hline
\end{tabular}

Note: $\mathrm{Cl}=$ confidence interval, $\mathrm{SMM}=$ severe maternal morbidity

*Number of pregnancies in propensity score-rematched cohorts were slightly lower than for the full model (total no. for age was $57007: n=11513$ with fertility treatment and $n=$ 47494 without fertility treatment; and total no. for singleton/multiple gestation was $58837: n=11448$ with fertility treatment and $n=47389$ without fertility treatment).

Table 3: Odds of a woman having 1, 2 or $\geq 3$ indicators of severe maternal morbidity between 20 weeks' gestation and 42 days after the index birth, by infertility treatment within the index pregnancy versus no infertility treatment, and by treatment subtype versus no infertility treatment

\begin{tabular}{|c|c|c|c|c|c|c|}
\hline \multirow[b]{2}{*}{ Exposure } & \multicolumn{2}{|c|}{ Women with 1 SMM indicator } & \multicolumn{2}{|c|}{$\begin{array}{l}\text { Women with } 2 \text { SMM } \\
\text { indicators }\end{array}$} & \multicolumn{2}{|c|}{$\begin{array}{l}\text { Women with } \geq 3 \text { SMM } \\
\text { indicators }\end{array}$} \\
\hline & $\begin{array}{c}\text { No. } \\
\text { (rate per 1000) }\end{array}$ & $\begin{array}{c}\mathrm{OR}^{\star} \\
(95 \% \mathrm{Cl})\end{array}$ & $\begin{array}{c}\text { No. } \\
\text { (rate per } \\
1000 \text { ) }\end{array}$ & $\begin{array}{c}\mathrm{OR}^{\star} \\
(95 \% \mathrm{Cl})\end{array}$ & $\begin{array}{l}\text { No. } \\
\text { (rate per } \\
\text { 1000) }\end{array}$ & $\begin{array}{c}\text { OR* }^{\star} \\
(95 \% \mathrm{CI})\end{array}$ \\
\hline \multicolumn{7}{|l|}{ Infertility treatment versus no infertility treatment } \\
\hline No infertility treatment $(n=47553)$ & $768(16.2)$ & 1.00 (ref.) & $164(3.4)$ & 1.00 (ref.) & $121(2.5)$ & 1.00 (ref.) \\
\hline Infertility treatment $(n=11546)$ & 247 (21.4) & $1.34(1.16-1.54)$ & $61(5.3)$ & $1.55(1.15-2.08)$ & $48(4.2)$ & $1.65(1.18-2.30)$ \\
\hline \multicolumn{7}{|c|}{ Infertility treatment subtype versus no infertility treatment } \\
\hline No infertility treatment $(n=47553)$ & $768(16.2)$ & 1.00 (ref.) & $164(3.4)$ & 1.00 (ref.) & $121(2.5)$ & 1.00 (ref.) \\
\hline Noninvasive infertility treatment $\dagger(n=5572)$ & $84(15.1)$ & $0.93(0.74-1.17)$ & $23(4.1)$ & $1.20(0.77-1.85)$ & $14(2.5)$ & $0.99(0.57-1.72)$ \\
\hline Invasive infertility treatment $\ddagger(n=5974)$ & $163(27.3)$ & $1.72(1.45-2.04)$ & $38(6.4)$ & $1.88(1.32-2.68)$ & $34(5.7)$ & $2.28(1.56-3.33)$ \\
\hline
\end{tabular}

showed an increased risk of severe maternal morbidity related to infertility treatment (OR 2.40, 95\% Cl 1.10-5.23). ${ }^{13} \mathrm{~A}$ third cohort study from Massachusetts that compared women who conceived through assisted reproductive technologies with those who were subfertile, untreated and pregnant also yielded an increased risk of severe maternal morbidity among singletons for both vaginal deliveries (OR 1.97, 95\% Cl 1.30-3.00) and cesarean deliveries (OR $1.75,95 \% \mathrm{Cl} 1.30-2.35) .{ }^{14}$ Differences in access to pregnancy care between US and Canadian health care systems, as well as patient demographics, may explain slight differences in estimates between our study and those of US-based researchers, heightening the importance of our findings to Canadian women considering infertility treatment and to their health care providers.
In Canada, recent provincial funding has permitted greater access to infertility treatment. ${ }^{8}$ Because such treatment is often accessed by perimenopausal women ${ }^{26}$ and those with reversible causes of infertility, including obesity, ${ }^{27}$ those receiving treatment have a higher prevalence of conditions such as diabetes mellitus and chronic hypertension. About 1 in 5 live births in Canada are to women over the age of 35 years, ${ }^{28}$ and $13 \%$ of all in vitro fertilization cycles in 2014 were performed solely for "advanced female age," furthering the risk of maternal and perinatal complications. ${ }^{29} \mathrm{~A}$ better understanding of the contribution of infertility treatment to severe maternal morbidity may lead to improved preventive and surveillance strategies for women who are at risk. 


\section{Limitations}

Study limitations included possible nondifferential misclassification of exposure, despite prior high data accuracy for this data source. ${ }^{30}$ Such misclassification is likely to be minor and would result in an attenuation of our risk estimates. Subfertility, as measured by fertility-related conditions, may have also been undercaptured, as shown by lower than expected rates of endometriosis and polycystic ovary syndrome (Table 1). Because women who received noninvasive infertility treatment had a similar rate of severe maternal morbidity and risk to those who became pregnant without infertility treatment suggests that women with noninvasive infertility treatment might prove to be a useful subfertile comparison group for future studies. However, severity of infertility - not captured with our approach - may also explain differences in adverse pregnancy outcomes between invasive and noninvasive treatment subgroups. ${ }^{31}$ Similarly, we lacked detailed information on the superovulation protocols used. Aggressive superovulation protocols have been linked with mortality in in vitro fertilization pregnancies; this may be a discriminating feature to include in future studies. ${ }^{32}$ We included diagnostic codes for obesity in our propensity score because high body mass index (BMI) is an independent risk factor for severe maternal morbidity. ${ }^{32}$ Body mass index was only available for 47939 matched pregnancies; therefore, the true proportion of obesity in our cohort is unknown. However, the interaction between prepregnancy BMI and infertility treatment may not be as influential on severe maternal morbidity as previously thought. ${ }^{33}$ Finally, we did not stratify our results by maternal ethnicity, which may modify the effect of infertility treatment.

\section{Conclusion}

Although severe maternal morbidity and maternal death are uncommon outcomes, our study suggests that women undergoing noninvasive infertility treatment, such as intrauterine insemination, are not at increased risk of these outcomes, whereas those undergoing in vitro fertilization are. Whether specific components of treatment using in vitro fertilization, such as the dose of ovarian hyperstimulation or fresh versus frozen embryo transfer, worsen maternal health, or whether the increased risk is a reflection of those who require or choose in vitro fertilization, remains to be determined. Nevertheless, studies comparing invasive with less invasive infertility treatment should extend their focus beyond rates of live births to encompass maternal health outcomes.

Women whose pregnancy was achieved by infertility treatment, especially in vitro fertilization, are at a somewhat higher risk of severe maternal morbidity or death. Further research should identify patient- and treatment-specific factors that might be modified to mitigate excess maternal risks.

\section{References}

1. Bushnik T, Cook JL, Yuzpe AA, et al. Estimating the prevalence of infertility in Canada. Hum Reprod 2012;27:738-46.

2. Talaulikar VS, Arulkumaran S. Reproductive outcomes after assisted conception. Obstet Gynecol Surv 2012;67:566-83.
3. Gunby J, Bissonnette F, Librach C, et al. Group of the Canadian Fertility Andrology Society. Assisted reproductive technologies (ART) in Canada: 2007 results from the Canadian ART Register. Fertil Steril 2011;95:542-7.e1-10

4. Messerlian C, Platt RW, Tan SL, et al. Low-tech assisted reproduction and the risk of pre-term birth in a hospital-based cohort. Fertil Steril 2015;103:81-8.e2

5. Sazonova A, Kallen K, Thurin-Kjellberg A, et al. Obstetric outcome after in vitro fertilization with single or double embryo transfer. Hum Reprod 2011;26: 442-50.

6. Wennerholm UB, Sazonova A, Kallen K, et al. Obstetric outcome in singletons after in-vitro fertilization with frozen-thawed embryos. Am J Obstet Gynecol 2012;1:S42.

7. Quebec Assisted Procreation Services. Québec: Gouvernement du Québec; 2017. Available: www.quebec.ca/en/family-and-support-for-individuals/ pregnancy-and-parenthood/assisted-procreation-services/ (accessed 2017 Dec. 11).

8. Ontario offering 50 government funded fertility treatment clinics. CBC News Toronto 2015 Dec. 21. Available: www.cbc.ca/news/canada/toronto/ontario -fertility-clinics-1.3374634 (accessed 2017 Sept. 6) .

9. Tulandi T, King L. Public funding and access to in-vitro fertilization. N Engl J Med 2013;368:1948-9.

10. Lisonkova S, Potts J, Muraca G, et al. Maternal age and severe maternal morbidity: a population-based retrospective cohort study. PLoS Med 2017;14: e1002307.

11. Canadian Perinatal Surveillance System. Ottawa: Public Health Agency of Canada; 2004. Available: www.canada.ca/en/public-health/services/injury-prevention/ health-surveillance-epidemiology-division/maternal-infant-health/canadian -perinatal-surveillance-system.html (accessed 2018 June 5).

12. Martin AS, Monsour M, Kissin DM, et al. Trends in severe maternal morbidity after assisted reproductive technology in the United States, 2008-2012. Obstet Gynecol 2016;127:59-66.

13. Wang ET, Ozimek J, Greene N, et al. Impact of fertility treatment on severe maternal morbidity. Fertil Steril 2016;106:423-6.

14. Belanoff C, Declercq ER, Diop H, et al. Severe maternal morbidity and the use of assisted reproductive technology in Massachusetts. Obstet Gynecol 2016; 127:527-34.

15. Vandenbroucke JP, von Elm E, Altman D, et al. Strengthening the Reporting of Observational Studies in Epidemiology (STROBE): explanation and elaboration. Epidemiology 2007;18:805-35.

16. Zou G. A modified Poisson regression approach to prospective studies with binary data. Am J Epidemiol 2004;159:702-6.

17. BORN's data quality report: 2012-2014 - executive summary. Ottawa: BORN [Better Outcomes Registry \& Network] Ontario; 2016. Available: http://datadictionary. bornontario.ca/assets/documents/Data\%20Quality/BORN\%20Data\%20Quality \%20Report\%202012-2014\%20-\%20Executive\%20Summary.pdf (accessed 2016 July 20).

18. Joseph KS, Liu S, Rouleau J, et al. Severe maternal morbidity in Canada, 2003 to 2007: surveillance using routine hospitalization data and ICD-10-CA codes. J Obstet Gynaecol Can 2010;32:837-46.

19. Austin PC. Using the standardized difference to compare the prevalence of a binary variable between two groups in observational research. Commun Stat Simul Comput 2009;38:1228-34.

20. Urquia ML, Wanigaratne S, Ray JG, et al. Severe maternal morbidity associated with maternal birthplace: a population-based register study. J Obstet Gynaecol Can 2017;39:978-87.

21. Medcalf KE, Park AL, Vermeulen MJ, et al. Maternal origin and risk of neonatal and maternal ICU admission. Crit Care Med 2016;44:1314-26.

22. Joseph KS, Fahey J; Canadian Perinatal Surveillance System. Validation of perinatal data in the Discharge Abstract Database of the Canadian Institute of Health Information. Chronic Dis Can 2009;29:96-100.

23. Austin PC. An introduction to propensity score methods for reducing the effects of confounding in observational studies. Multivariate Behav Res 2011; 46:399-424.

24. Lazariu V, Nguyen T, McNutt LA, et al. Severe maternal morbidity: a populationbased study of an expanded measure and associated factors. PLoS One 2017;12:e0182343. 
25. Ray JG, Urquia ML, Berger H, et al. Maternal and neonatal separation and mortality associated with concurrent admissions to intensive care units. CMAJ 2012;184:E956-62.

26. Ethics Committee of the American Society for Reproductive Medicine. Oocyte or embryo donation to women at advanced age: a committee opinion. Fertil Steril 2013;100:337-40.

27. Craig LB, Peck JD, Bullock S, et al. How large is too large: association of obesity with fecundability in women undergoing intrauterine insemination. Fertil Steril 2011;96(Suppl 1):S89.

28. Live births, by age of mother. Ottawa: Statistics Canada; 2016. Available: www150.statcan.gc.ca/t1/tbl1/en/tv.action?pid=1310041601 (accessed 2018 Aug. 23).
29. Cleary-Goldman J, Malone FD, Vidaver J, et al. Impact of maternal age on obstetric outcome. Obstet Gynecol 2005;105:983-90.

30. Baldur-Felskov B, Kjaer SK, Albieri V, et al. Psychiatric disorders in women with fertility problems: results from a large Danish register-based cohort study. Hum Reprod 2013;28:683-90.

31. Basso O, Weinberg CR, Baird DD, et al. Subfecundity as a correlate of preeclampsia: a study within the Danish National Birth Cohort. Am J Epidemiol 2003;157:195-202.

32. Braat DDM, Schutte JM, Bernardus RE, et al. Maternal death related to IVF in the Netherlands 1984-2008. Hum Reprod 2010;25:1782-6.

33. Dayan N, Fell DB, Guo Y, et al. Severe maternal morbidity in women with high BMI in IVF and unassisted singleton pregnancies. Hum Reprod 2018;33:1548-56.

\section{Competing interests: None declared.}

This article has been peer reviewed.

Affiliations: Department of Medicine and Research Institute (Dayan), Department of Obstetrics and Gynecology (Basso), McGill University Health Centre; Department of Epidemiology, Biostatistics and Occupational Health (Dayan, Basso), McGill University, Montréal, Que.; Department of Obstetrics and Gynaecology, and School of Population and Public Health (Joseph), University of British Columbia, Vancouver, BC; Children's Hospital of Eastern Ontario Research Institute (Fell); School of Epidemiology and Public Health (Fell), University of Ottawa, Ottawa, Ont.; Department of Medicine and Obstetrics and Gynecology (Laskin), University of Toronto; TRIO Fertility (Laskin); ICES (Park, Luo, Guan, Ray, Fell); Department of Medicine (Ray), St. Michael's Hospital, Toronto, Ont

Contributors: All of the authors contributed substantially to this study. Natalie Dayan designed the study, interpreted analyses, and wrote and revised the manuscript. Joel Ray designed the study with Natalie Dayan and interpreted analyses. K.S. Joseph, Alison Park, Olga Basso, Deshayne Fell and Carl Laskin helped with study design and data interpretation. Jin Luo and Jun Guan helped with study design and cohort creation, and performed data analyses. All of the authors revised the manuscript critically for important intellectual content, approved the version to be published and agreed to be accountable for all aspects of the work.

Funding: This study was supported by funding from the Canadian Institutes of Health Research (grant no. 15139). Natalie Dayan is supported by a Fondation de Recherche du Québec - Santé (FRQS) Chercheur Boursier Clinicien award. K.S. Joseph is supported by an Investigator award from the BC Children's Hospital Research Institute and an Applied Chair in Reproductive, Child \& Youth Health Services and Policy Research from the Canadian Institutes of Health Research (APR-126338). This study was also supported by ICES, which is funded by an annual grant from the Ontario Ministry of Health and Long-Term Care (MOHLTC).

Data sharing: The data set from this study is held securely in coded form at ICES. Although data-sharing agreements prohibit ICES from making the data set publicly available, access may be granted to those who meet prespecified criteria for confidential access, available at www.ices.on.ca/DAS. The full data set, creation plan and underlying analytic code are available from the authors upon request, with the understanding that the computer programs may rely upon coding templates or macros that are unique to ICES and are therefore either inaccessible or may require modification.

Acknowledgements: The authors thank Dr. Janet Takefman for review of the manuscript from the perspective of the infertile patient, and Dr. Gabriel Shapiro and Hiba Jekki for their help with figure and manuscript formatting.

Disclaimer: Parts of this material are based on data or information compiled and provided by Canadian Institute for Health Information (CIHI). However, the analyses, conclusions, opinions and statements expressed in the material are those of the authors, and not necessarily those of $\mathrm{CIHI}$. This study is based, in part, on data provided by the Better Outcomes Registry \& Network (BORN), part of the Children's Hospital of Eastern Ontario. The interpretation and conclusions contained herein do not necessarily represent those of BORN Ontario. This study was supported by ICES, which is funded by an annual grant from the Ontario Ministry of Health and LongTerm Care (MOHLTC). The opinions, results and conclusions reported in this paper are those of the authors and are independent from the funding sources. No endorsement by ICES or the Ontario MOHLTC is intended or should be inferred.

Accepted: Dec. 19, 2018

Correspondence to: Natalie Dayan, Natalie.dayan@mcgill.ca 